\title{
P115 AND THE NUMBER OF THE BEAST
}

\author{
P. J. Williams
}

\begin{abstract}
Summary
In Revelation 13:18 the occurrence of the number 616 in $\mathcal{P}^{15}$ has been taken as offering support to the view that the number refers to Nero. Here, an alternative or perhaps additional explanation of the number 616 is given by the suggestion that this number visually mimics designations of Jesus.
\end{abstract}

\section{Introduction}

The number of conjectures as to the significance of the number of the Beast in Revelation 13:18 almost seems to exceed 666. Scholars now generally agree that a solution to the question of its meaning will need to invoke some form of gematria, since the letters of both the Greek and Hebrew alphabets had numerical significance. Irenaeus records, with varying levels of approval, ${ }^{1}$ the suggestions that 666 corresponded

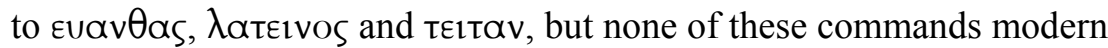
support. Recent scholarship has more readily given attention to various possibilities based on the Hebrew alphabet.

One of the consistently popular proposals of the modern period one which Charles attributes to four scholars independently - is that

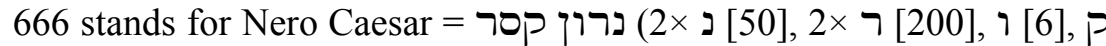
[100], $\square[60] .^{2}$ This interpretation has gained support through the existence of a textual variant giving the number as 616 found in $\mathrm{ms} \mathrm{C}$ and in

1 Irenaeus, Adv. Haer. 5.30.3.

2 R. H. Charles, The Revelation of St. John (ICC; Edinburgh: T \& T Clark, 1920): 367. The scholars mentioned by Charles are Holtzmann, Benary, Hitzig and Reuss. Suetonius, Nero 39, demonstrates that there was an ancient interest in the numerical value of Nero's name. 
manuscripts known to Irenaeus. ${ }^{3}$ This reading has recently been bolstered by the publication of $\mathcal{P}^{115}$ (POxy 4499), dated by its editor J. Chapa to the late third or early fourth century. The manuscript is now the oldest surviving manuscript witness to this reading. ${ }^{4}$ Whether or not it is secondary, the reading 616 can be explained as a variant of Nero Caesar, spelling the name Nero (נרו) as in Latin rather than Neron

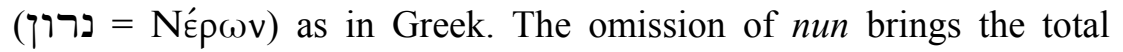
down by exactly 50 from 666 to 616 .

However, conclusive support for this interpretation should not be taken from $\mathcal{P}^{115}$, because the number 616 could also have arisen for other reasons. G. K. Beale opts for the safety of a rhetorical question when he asks ' $\ldots$ is it coincidence that the numerical value in Hebrew of the Greek word Anpiov ("beast") is 666?'5 This number is calculated

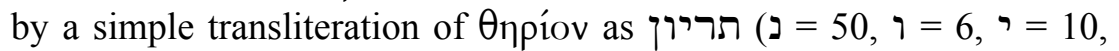
\urcorner$=200, \Omega=400$ ). Whether or not this is a coincidence, this interpretation allows for an alternative. Revelation 13:18 reads ó 'É $\chi \omega v$ voũv

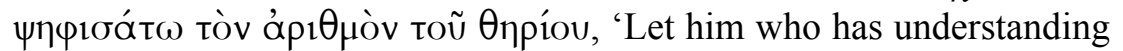
calculate the number of the Beast.' If we retain the word 'beast' in the case in which it occurs in Revelation 13:18, i.e. Onpíou, and transliterate it into Hebrew we get תריר, which has a numerical value of $616 .{ }^{6}$ The interpretation that the number of the Beast is simply the Greek word for 'beast' written in Hebrew characters therefore works with both numbers, 666 and 616, as does the interpretation Nero Caesar. The reading of $\mathcal{P}^{115}$ should not therefore be taken as giving exclusive support to the interpretation Nero Caesar. The multiplicity of explanations naturally raises the question as to how many explanations can be simualtaneously applied, since they need not exclude each other.

3 Irenaeus, Adv. Haer. 5.30.1.

4 J. Chapa in The Oxyrhynchus Papyri, Volume 66, ed. N. Gonis, J. Chapa, et al. (London: British Academy, 1999): 10-35 The relevant image can be seen via: http://www.papyrology.ox.ac.uk/POxy

On this papyrus and others published with it see further Peter M. Head 'Some Recently Published NT Papyri from Oxyrhynchus: An Overview and Preliminary Assessment', Tyndale Bulletin 51 (2000): 1-16.

5 G. K. Beale, The Book of Revelation (NIGTC; Grand Rapids: Eerdmans, 1999): 723.

6 I arrived at this equivalent of 616 on my own, but subsequently found that it had already been reached by Michael Oberweis in 'Die Bedeutung der neutestamentlichen "Rätselzahlen" 666 (Apk 13 ${ }^{18}$ ) und 153 (John 21 ${ }^{11}$ ),' ZNW 77 (1986): 226-41, esp. 235-36. The fact that what Oberweis calls a 'verblüffend einfache Lösung des Problems' can be arrived at independently is an additional support for its plausibility. 


\section{New Proposal}

The proposal made here is that discussion of the significance of the number 616 may not have given adequate attention to the visual impact made by the number. In $\mathcal{P}^{115}$ the number of the Beast is written in digits as $\overline{\chi^{1} \zeta} .{ }^{7}$ The line over the number indicates they are digits, but elsewhere in the manuscript such a line can have the function of indicating a nomen sacrum. In fact, although scholars since Ludwig Traube have distinguished the function of the line over numbers from the function of the line over nomina sacra, it is not clear that scribes were conscious of this distinction, since in both cases the line indicates that what is pronounced is different from the letters written and functions as an abbreviation, even if it was not intended as such.

In the $\mathcal{P}^{115} \overline{\chi^{1} S}$ is visually reminiscent of the nomina sacra $\overline{\chi S}$ 'Christ' and $\overline{15}$ 'Jesus', which frequently occur together. The digit for the unit six, digamma, and the final letter of these nomina sacra, sigma, are not written differently in this manuscript and in other sources, making the visual resemblance closer. The nominative nomina sacra for xpıбтós and 'Inooũs respectively have longer and shorter forms $(\overline{\chi \rho \zeta}, \overline{\chi \zeta}, \overline{1 \eta \zeta}$ and $\overline{1 \zeta})$, but within $\mathcal{P}^{115}$ no nomina sacra of either of these terms are extant and it is therefore impossible to be confident that the shorter forms $\overline{X S}$ and $\overline{1 \zeta}$ would have been used. Nevertheless, even if longer forms were used elsewhere in the manuscript, readers would probably have been struck by the visual resemblance of the number to common designations of Jesus. We must therefore consider whether the number as written in $\mathcal{P}^{115}$ could be a deliberate mimicking of the appearance of these nomina sacra. ${ }^{8}$

Thus, given the alternatives that exist, $\mathcal{P}^{115}$ could be seen as supporting a number of proposals and does not exclusively support any single one, such as the Nero redivivus interpretation.

7 In the apparatus of NA27 the final digit is given in a form identical to the final sigma, which, of course, did not exist at the time of the writing of the manuscript.

8 The reason for the eta in $\mathcal{P}^{115}$ just before the number in question remains puzzling. It appears to have a short line over it, which may indicate deletion, a function played by a line over a word in 2:27 and 3:10. 